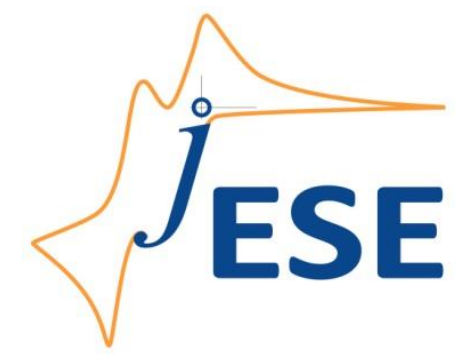

Open Access : : ISSN 1847-9286

www.jESE-online.org

Original scientific paper

\title{
Binder-less activated carbon electrode from gelam wood for use in supercapacitors
}

\author{
NIRWAN SYARIF**** ${ }^{*}$, IVANDINI A. TRIBIDASARI* and WIDAYANTI WIBOWO* \\ *Department of Chemistry, Faculty of Mathematics and Natural Sciences, University of Indonesia, \\ Indonesia \\ **Department of Chemistry, Faculty of Mathematics and Natural Sciences, Sriwijaya University, \\ Indonesia
}

${ }^{\square}$ Corresponding Author: E-mail: E-mail: nnsyarif@gmail.com; Tel.: +62-711-580269; Fax: +62-711-580069

Received: August 8, 2012; Revised: November 30, 2012; Published: : April 19, 2013

\begin{abstract}
This work focused on the relation between the porous structure of activated carbon and its capacitive properties. Three types of activated carbon monoliths were used as the electrodes in a half cell electrochemical system. One monolith was produced from activated carbon and considered to be a binder-less electrode. Two others were produced from acid and high pressure steam oxidized activated carbon. The micrographs clearly indicate that three electrodes have different porous structures. Both porosity and surface area of carbons increased due to the formation of grains during oxidation. This fact specified that an acid oxidized carbon monolith will have relatively higher capacitance compared to non-oxidized and steam oxidized monoliths. Maximum capacitance values for acid, steam oxidized and non-oxidized electrodes were 27.68, 2.23 and $1.20 \mathrm{Fg}^{-1}$, respectively.
\end{abstract}

\section{Keywords}

pyrolysis; voltammogram; surface oxidation; capacitance; micropore.

\section{Introduction}

Supercapacitors have become the focus attention of many researchers for decades due to their potential application as energy storage devices in relation to their high energy density, great power density and long cycle life. Much effort has been done to develop advanced carbons to meet the demand for high performance supercapacitors [1]. Fossil- and organic-based carbonaceous materials are amongst the most widely used starting or precursor materials for supercapacitor electrodes because they are relatively inexpensive and easy to fabricate. These electrode materials 
also have large specific surface areas, good electrical conductivity and excellent chemical stability. The carbonaceous materials extracted from biomass such as fruit peels, beans, plant shells, bamboo, woods, natural fibers and bagasse have been studied for supercapacitor carbon electrodes.

The fabrication of carbon electrodes for supercapacitors, normally requires an addition of a polymer matrix in order to bind together the carbon particles into monolithic (pellet) form. This addition blocks a part of the carbon pores [2] and additionally causes an increase in the electrical resistivity [3]. Furthermore, the use of polymer binder makes the product more expensive and environmentally less friendly. Therefore, the carbon electrode without the use of any binding agent is highly recommended in order to be potentially used in supercapacitor applications, because they might have lower resistance in the absence of a polymeric binder and they are also of lower cost [4].

In most cases, the physicochemical properties of the carbon electrode, such as its structure, electrical conductivity and porosity, was improved by an activation process. The physical activation is normally carried out by treatment of the carbonized sample using gas atmosphere (such as $\mathrm{CO}_{2}$, $\mathrm{N}_{2}$ and water steam) under a moderately higher temperature of $800-1000{ }^{\circ} \mathrm{C}$ to improve the internal porosity [5].

In this paper, we report the preparation and characterization of free binder activated carbon monolith electrodes prepared from Gelam wood, which were activated by physical process under $\mathrm{N}_{2} / \mathrm{CO}_{2}$ gas and followed by surface oxidation using nitric acid and high pressure steam. It should be emphasized that the use of this activated carbon for supercapacitor was not yet reported.

\section{Experimental}

\section{Activated carbon and electrode preparation}

Activated carbons were prepared from the gelam wood piles obtained from local timber industry. Non-bark wood piles sizes $10 \mathrm{~cm}$ length and $5 \mathrm{~cm}$ diameter was used in the production of activated carbon rod. Pyrolysis was conducted after preheating process and followed by second pyrolysis for activation process. Wood was preheated in the oven at $230-260{ }^{\circ} \mathrm{C}$ for a half hour. Wood were carbonized by heating from 40 to $700{ }^{\circ} \mathrm{C}$ at rate of $3{ }^{\circ} \mathrm{C}$ per minute under atmosphere of nitrogen flow and controlled for $1 / 2-1$ hour at peak temperature. Nitrogen was flowed to the reactor at rate of $1 \mathrm{~mL} \mathrm{~min}$. The heating procedure was repeated but using $\mathrm{CO}_{2}$ as the atmosphere to produce activated carbon. This activated carbon was labeled as CCP.

CCP was cut into pellets of $5 \mathrm{~mm}$ in thickness by using a mini-circular electric knife. CCP was subjected for surface oxidation using concentrated nitric acid and high pressure steam, both labeled as $\mathrm{CCPHNO}_{3}$ and CCPWOT respectively. Activated carbons were oxidized in reflux system for 3 hours using concentrated nitric acid at $60^{\circ} \mathrm{C}$. The high pressure steam oxidation was conducted in the hydrothermal reactor for 16 hours at $200{ }^{\circ} \mathrm{C}$. The products were washed with abundant de-mineralized water and dried. These three types of activated carbon pallets were used as electrodes.

\section{Surface characterization}

The characterization of activated carbons was carried out through physical adsorption of nitrogen gas at $77 \mathrm{~K}$, using a conventional volumetric system (Micromeritics ASAP 2400 instrument). The surface area based on nitrogen isotherms was calculated using the BET equation, and using the "t" method. Scanning Electron Microscopy (SEM) and Energy Dispersive X-ray analysis (EDX) were used to observe the structural morphology and composition of activated carbon, respectively. Hitachi S-4000 field emission SEM was used for this analysis, operated at 30 $\mathrm{keV}$. Uncoated samples were subjected for SEM observation. 
The Boehm titration method was applied to determine the acid and basic sites in the activated carbons [6]. The total acid sites were neutralized with $0.1 \mathrm{M} \mathrm{NaOH}$ solutions, and the basic sites were neutralized with a $0.1 \mathrm{M} \mathrm{HCl}$ solution. The reaction between reagents and acidic oxygenatedfunctional groups on the surface is based on the difference strength of the acid/base. The strength order of acidic and basic groups is as follow: carboxyl > lactone > phenol. The carboxylic and lactonic sites were titrated with a $0.1 \mathrm{MNa}_{2} \mathrm{CO}_{3}$ solution, the carboxylic sites were titrated with a $0.1 \mathrm{M} \mathrm{NaHCO}_{3}$ solution and the phenolic sites were determined by the difference. For each determination, $50 \mathrm{~mL}$ of the solution was added to one gram of activated carbon in a glass container. The container was inserted into vortex shaker for over one day. A $10 \mathrm{~mL}$ sample was titrated with $0.1 \mathrm{M}$ of $\mathrm{HCl}$ or $\mathrm{NaOH}$ solutions.

\section{Electrochemical measurement}

Electrochemical tests of the electrodes were conducted using the cyclic voltammetry technique using a three electrode configuration on a potentiostat instrument (eDAQ Pty Ltd, model EA161). $\mathrm{Ag} / \mathrm{AgCl}$ electrode was used as reference electrode and a platinum rod was used as the counter electrode. Cyclic voltammetry tests were conducted at scan rates of 2, 5, 10, 20, 50, and $100 \mathrm{mV} \mathrm{s}^{-}$ ${ }^{1}$ with potential windows ranging from -1 to $1 \mathrm{~V}$ in 1,2 , and $4 \mathrm{~mol} \mathrm{~L}^{-1} \mathrm{KOH}$ or $\mathrm{H}_{2} \mathrm{SO}_{4}$ aqueous solution as electrolytes. Considering that the anodic voltammetric charges and cathodic voltammetric charges are not the same in the shape of voltammogram curve, the average specific capacitance of the electrode was calculated using integral area approximation

$$
C_{\text {avg }}=\frac{\Delta Q}{w \Delta V}=\frac{\int I d V}{s \Delta V w}
$$

Where $\Delta Q$ is the total amount of the charge accumulated over a potential window, $\Delta V, w$ is the mass of active material in one electrode, $l$ is the current, and $s$ is the potential scan rate. Hence $\int I d V$ is integral area of voltammogram curve.

\section{Results and Discussion}

\section{Pore structures and chemical characteristics}

Three carbon electrodes, namely CCP, CCPHNO3 and CCPWOT, were prepared from Gelam wood activated carbon. The pores and grains were formed during preparation affecting the properties of electrodes. Pores act as the entrance of small molecules penetrated deeper into the micro pores [7]. Penetrating water steam and gases made some cracks and led to changed porous structures [8].

The porous structure of carbon can be characterized by the adsorption isotherms and pore size distribution plot [9]. The adsorption isotherms plot for the three electrodes (Figure 1A) are type I represented by a flat curve, indicating micropores. The broadening of the knee in the very low relative pressures range in $\mathrm{CCPHNO} 3$ indicates that the microporosity of the carbon became wider upon acid oxidation treatment (Figure 1A (b)). Acid oxidation burst opening pore in carbon surface and increasing pore volume two times larger. In the other hand, some micro pores vanished (Figure $1 \mathrm{~A}(\mathrm{c})$ ) and pore size distribution became narrow (Figure 1B (c)) upon hydrothermal treatment due to fracture of the bulky network and the pore walls [10]. This fracturing blocked some pores and affected the pore structures and surface functional groups of carbon. 

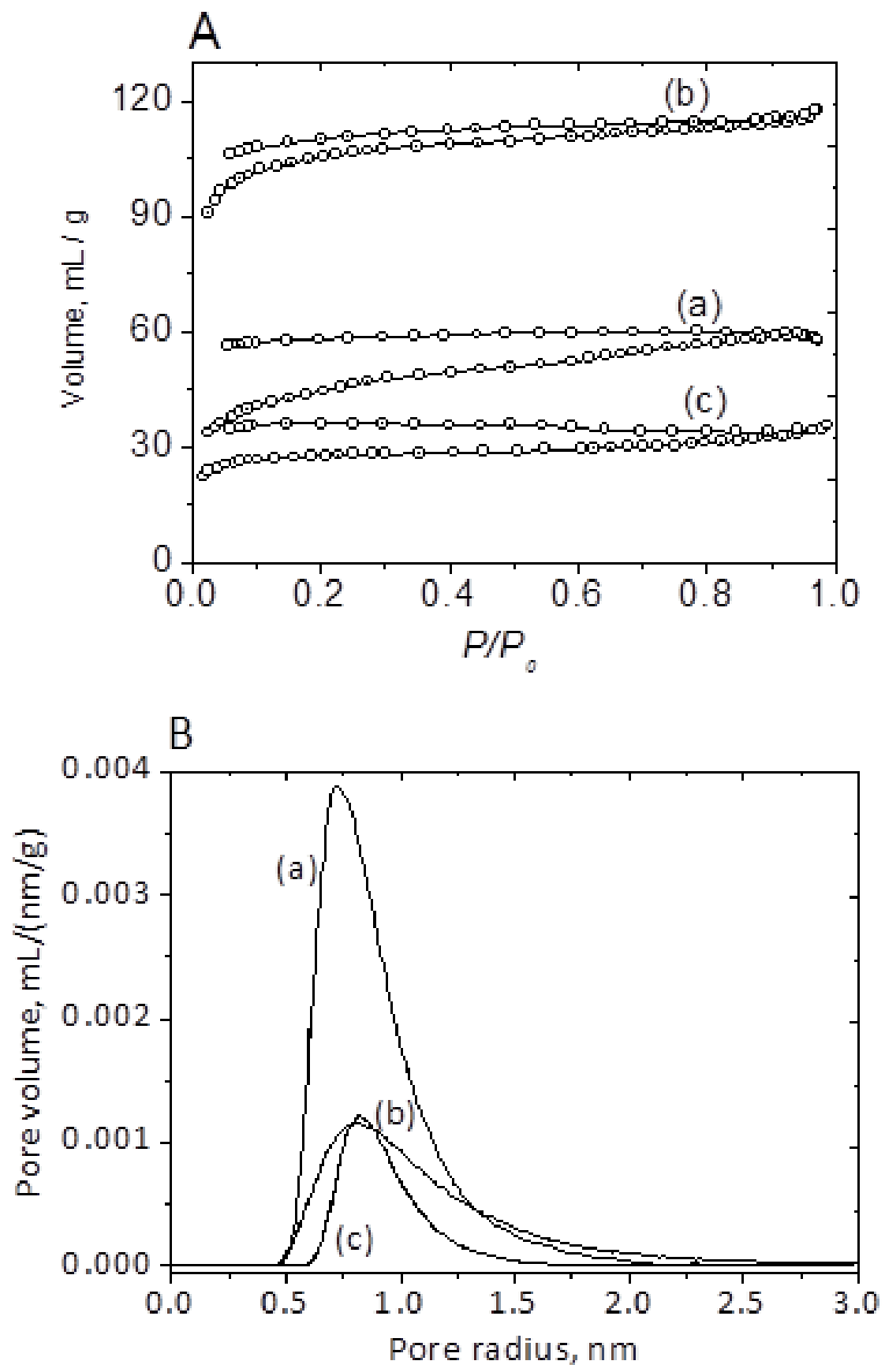

Figure 1. (A) Nitrogen adsorption-desorption on the surface of electrodes (B) Pore size distribution for (a) CCP, (b) CCPHNO3 and (c) CCPWOT.

Table 1 shows the changes in surface area, pore volume, and surface functional groups as a result of oxidation treatments. CCPHNO3 had the highest BET surface $\left(337.1 \mathrm{~m}^{2} \mathrm{~g}^{-1}\right)$, and a total pore volume measured at $P / P_{0}=0.95$ of $0.185 \mathrm{~cm}^{3} \mathrm{~g}^{-1}$, most of the pores being micropores $(81.50 \%)$, with an average pore width of $1.1 \mathrm{~nm}$. On the other hand, CCPWOT exhibited the lowest BET surface $\left(88.800 \mathrm{~m}^{2} \mathrm{~g}^{-1}\right)$, with a much lower total pores volume $\left(0.014 \mathrm{~cm}^{3} \mathrm{~g}^{-1}\right)$ and a narrower pore width $(1.408 \mathrm{~nm})$. A pore size distribution in the range of micropore in which larger than the size of two solvated ions, was then identified as a way of improving the energy density and the power capability [11], whereas mesopores improved the ionic mass transport inside the bulk of carbon. Therefore, it was assumed that a good balance between micro- and mesoporosity was needed to maximize capacitance [12]. Some capacitance values from the literature are 
provided to clarify the relationship between pore structure and capacitance. It can also be seen from the Table 1 that the some capacitance values obtained in this study are smaller than those obtained from the literatures.

Table 1. Surface and electrochemical properties of the CCP, CCPHNO3 and CCPWOT electrodes.

\begin{tabular}{|c|c|c|c|c|c|c|c|c|}
\hline \multirow{2}{*}{ Electrode } & \multirow{2}{*}{$S_{B E T} m^{2} g^{-1}$} & \multirow{2}{*}{$V_{\text {total }} / \mathrm{cm}^{3} \mathrm{~g}^{-1}$} & \multirow{2}{*}{$\begin{array}{l}\text { micro pore } \\
\text { content, \% }\end{array}$} & \multicolumn{4}{|c|}{ Functional groups concentration, $\mathrm{mmol} \mathrm{g}^{-1}$} & \multirow{2}{*}{$\begin{array}{l}C_{\text {sp, max }} \\
\mathrm{F} \mathrm{g}^{-1}\end{array}$} \\
\hline & & & & fenolic & lactonic & carboxylic & base & \\
\hline CCP & 149.848 & 0.093 & 56.249 & 0.200 & 3.85 & 0.00 & 0.24 & 1.22 \\
\hline CCPHNO3 & 337.116 & 0.185 & 81.499 & 0.100 & 3.08 & 0.20 & 0.19 & 27.68 \\
\hline CCPWOT & 88.800 & 0.014 & 28.306 & 0.200 & 3.40 & 0.10 & 0.22 & 2.23 \\
\hline $\begin{array}{l}\text { Carbon from } \\
\text { sucrose [13] }\end{array}$ & 2749.0 & 2.01 & & & & & & 233 \\
\hline $\begin{array}{l}\text { Carbon from } \\
\text { sago waste [14] }\end{array}$ & 1408.2 & 0.897 & & & & & & 64.1 \\
\hline $\begin{array}{l}\text { Carbon from } \\
\text { coal [14] }\end{array}$ & 179.2 & 0.073 & & & & & & 16.2 \\
\hline
\end{tabular}

Furthermore, the specific surface area of the CCPHNO3 electrode as listed in Table 1 is $337.116 \mathrm{~m}^{2} \mathrm{~g}^{-1}$, which is higher than that of the CCP and CCPWOT electrode, i.e. 149.85 and $88.80 \mathrm{~m}^{2} \mathrm{~g}^{-1}$, respectively. The Boehm analysis reveals that the three electrodes have similar amounts of functional groups, except for the carboxylic and lactone groups. A computational study was undertaken on the effect of the two functional groups on the structure of graphite basal. The study found that the $\mathrm{COOH}$ functional groups that fill the vertical plane will bend graphite layer led to reduced effectiveness of electron transfer between layers. These functional groups improved capacitive processes of the carbon [15], and facilitated the penetration of the electrolyte ions into the interior pores. Although the CCPWOT electrode has many more functional groups, however, many more pores were vanished and the surface area was decreased, leading to a decrease in the capacitance of electrode. Furthermore, changes in the carbon pore structure can be clearly seen as surface morphology by using electron microscope.

The micrographs clearly indicate that the three electrodes have different surface morphologies. Figure $2 \mathrm{a}$ and $2 \mathrm{~d}$ show the analysis of the CCP microstructure by SEM. They revealed continuous and smooth surface of the CCP with less grain boundaries wood (Figure $2 \mathrm{a}$ and $2 \mathrm{~d}$ ) due to the limited process of opening pore in line with the nature of the wood. The other SEM pictures show the opening pores in the surface of the carbon which occurred when CCP was treated with nitric acid (CCPHNO3), especially the oxidation of low molecular weight carbon. These SEM images of CCPHNO3 show irregular sizes and flaky grains in which the structures tend to form voids between the grains (Figure $2 \mathrm{~b}$ and e). The number of grains and micropores of $\mathrm{CCPHNO} 3$ are higher than those of CCPWOT and CCP, due to the reaction between low molecular weight carbon fragments with nitrogen. The oxidation reaction generated volatile molecules that leave the pores behind after volatilization. Furthermore, SEM images of CCPWOT show more regular size and relatively uniform (Figure $2 \mathrm{c}$ and f). This porous structure, i.e. pore volume, surface area and pore size distribution along with functional groups on the surface of carbon are regarded as the important factors which determined the properties of capacitive processes, i.e. ionic accessibility, electrical double layer and redox reactions [16-18]. 


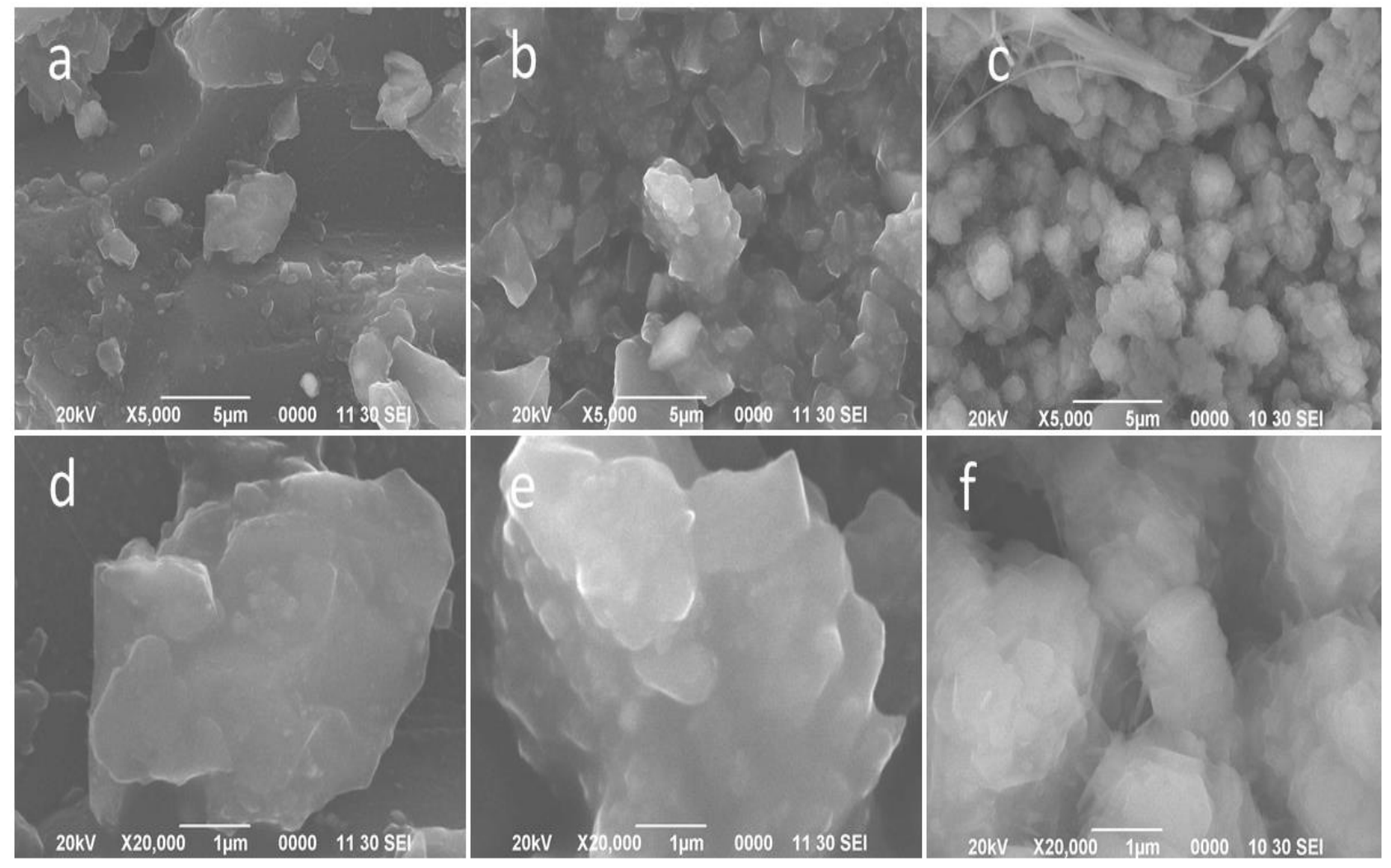

Figure 2. SEM images for CCP ( $a$ and $d)$, CCPHNO3 ( $b$ and $e$ ), and CCPWOT (c and $f$ )

\section{Electrochemical performance}

Cyclic voltammetry tests were conducted at scan rates of 2, 5, 10, 20, 50, and $100 \mathrm{mV} \mathrm{s}^{-1}$ with potential windows ranging from -1 to $1 \mathrm{~V}$ versus $\mathrm{Ag} / \mathrm{AgCl}$ in 1,2 , and $4 \mathrm{~mol} \mathrm{~L}^{-1} \mathrm{KOH}$ or $\mathrm{H}_{2} \mathrm{SO}_{4}$ aqueous solution to quantify the electrochemical performance of $\mathrm{CCP}, \mathrm{CCPHNO}_{3}$ and $\mathrm{CCPWOT}$ electrodes. As shown in Figure 3 and 4, no pronounced reversible reduction oxidation peak can be observed from voltammograms for the three electrodes. The shape of the voltammograms was different from one to another.

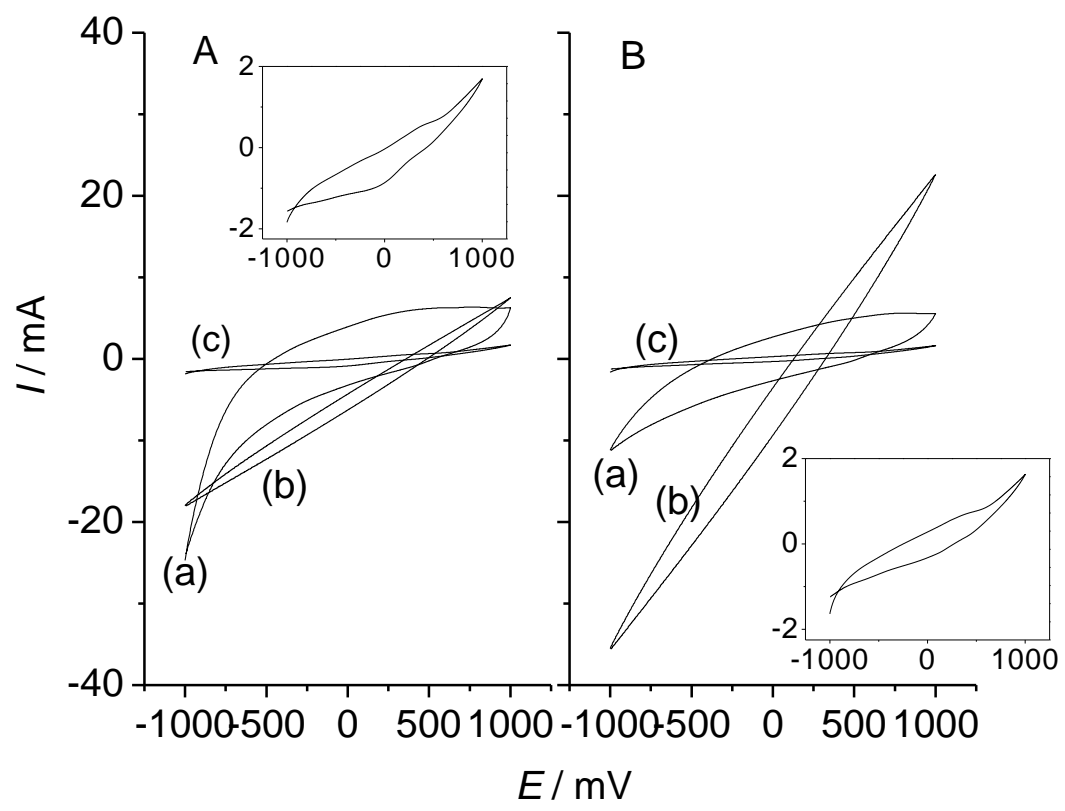

Figure 3. CV Curve of carbon electrodes (a) CCP, (b) CCPHNO3 and (c) CCPWOT in the $\mathrm{H}_{2} \mathrm{SO}_{4} 1 \mathrm{M}$

(A) and $4 M$ (B). Scan rate was $20 \mathrm{mV} \mathrm{s}^{-1}$. Inset: magnification of voltammogram (c). 
The voltammogram of the CCPWOT electrode was relativelylower compared to the other two curves. Therefore the oxidation treatment under water steam reduced the capacitance. On the other hand, the highest current of $\mathrm{CCPHNO}$ electrode points to the largest capacitance. The changes in capacitance occurred on the electrode after the oxidation process was associated with changes in pore volume of carbon, as previously described. Oxidation using strong acid clarified the existence of the Faraday process (redox reaction) that occurred at the carbon as described by other authors [19]. The voltammograms shape of CCPHNO3 in both acid and base electrolytes are much the same, which means that the tendency to establish a redox reaction was similar. The voltammogram area in Figure 3 shows the decrease in capacitance at high concentrations of $\mathrm{H}_{2} \mathrm{SO}_{4}$. By contrast, the capacitance of the electrodes increased at a low concentration $\mathrm{KOH}$ (Figure 4).

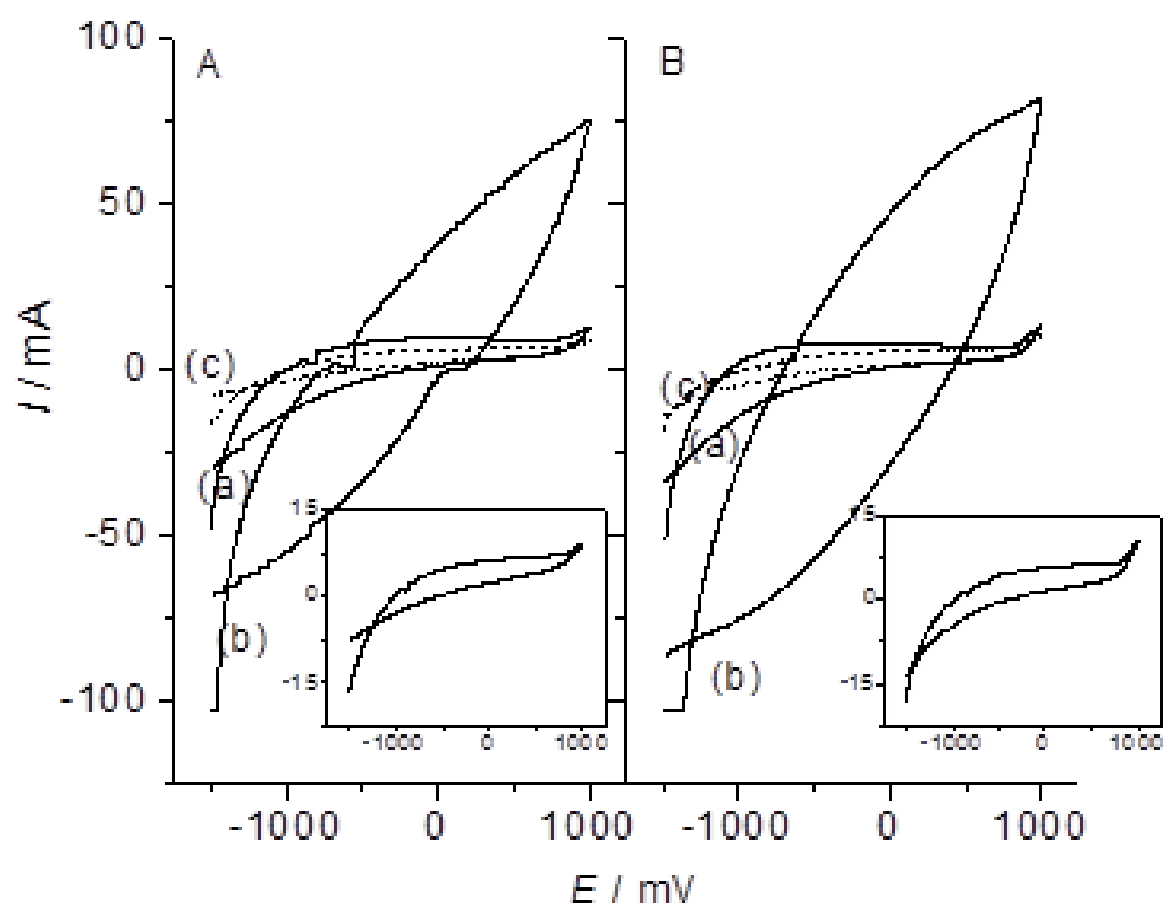

Figure 4. Voltammogram of carbon electrodes (a) CCP, (b) CCPHNO3 and (c) CCPWOT in the $\mathrm{KOH} 2 \mathrm{M}(\boldsymbol{A})$ and $4 \mathrm{M}(\boldsymbol{B})$. Scan rate was $5 \mathrm{mV} \mathrm{s}^{-1}$. Inset: magnification of voltammogram (c).

Calculations of specific capacitances for all electrodes at various scan rates in the $\mathrm{H}_{2} \mathrm{SO}_{4}$ solution are presented in Figure 5. At the $5 \mathrm{mV} \mathrm{s}^{-1}$ scans rate in $\mathrm{H}_{2} \mathrm{SO}_{4}$, the CCP electrode had a specific capacitance of $1.2 \mathrm{~F} \mathrm{~g}^{-1}$, while at a scan rate of $100 \mathrm{mV} \mathrm{s}^{-1}$ this was $0.22 \mathrm{~F} \mathrm{~g}^{-1}$. Capacitance values of the CCPWOT electrode (Figure $5 \mathrm{~B}$ ) at $5-10 \mathrm{mV} \mathrm{s}^{-1}$ were lower than that of CCP (Figure $5 \mathrm{~A}$ ), but were higher at 20-100 mV s${ }^{-1}$. The capacitance values of CCP and CCPWOT electrodes were much smaller than those of the $\mathrm{CCPHNO} 3$ electrode (Figure $5 \mathrm{C}$ ). Maximum capacitance for nonoxidized, steam and acid oxidized electrodes were $1.22,0.63$ and $2.57 \mathrm{Fg}^{-1}$, respectively. These values occurred at $5 \mathrm{mV} \mathrm{s}^{-1}$.

Plots of the electrodes specific capacitances vs. scan rate in $\mathrm{KOH}$ are presented in Figure 6. Capacitances of $\mathrm{CCP}$ in $\mathrm{KOH}$ were much the same as those in $\mathrm{H}_{2} \mathrm{SO}_{4}$ both at low and high scan rates. Contrary to what occurred in the $\mathrm{H}_{2} \mathrm{SO}_{4}$, the capacitance values of the CCPWOT electrode (Figure 6B) were higher than those of CCP (Figure 6A), both at low and high scan rates. Capacitance values of CCP and CCPWOT electrodes were also much smaller than those of the CCPHNO3 electrode. Plot of specific capacitance of CCPHNO3 in $\mathrm{KOH}$ was discrete (Figure 6C) due to instability of the system, especially at a scan rate higher than $10 \mathrm{mV} \mathrm{s}^{-1}$. A stable voltammogram 
was only obtained at a scan rates higher than $40 \mathrm{mV} \mathrm{s}^{-1}$ at $1 \mathrm{M} \mathrm{KOH}$. Capacitance value for acid and steam oxidized electrodes were 2.23 and $27.68 \mathrm{~F} \mathrm{~g}^{-1}$, respectively.
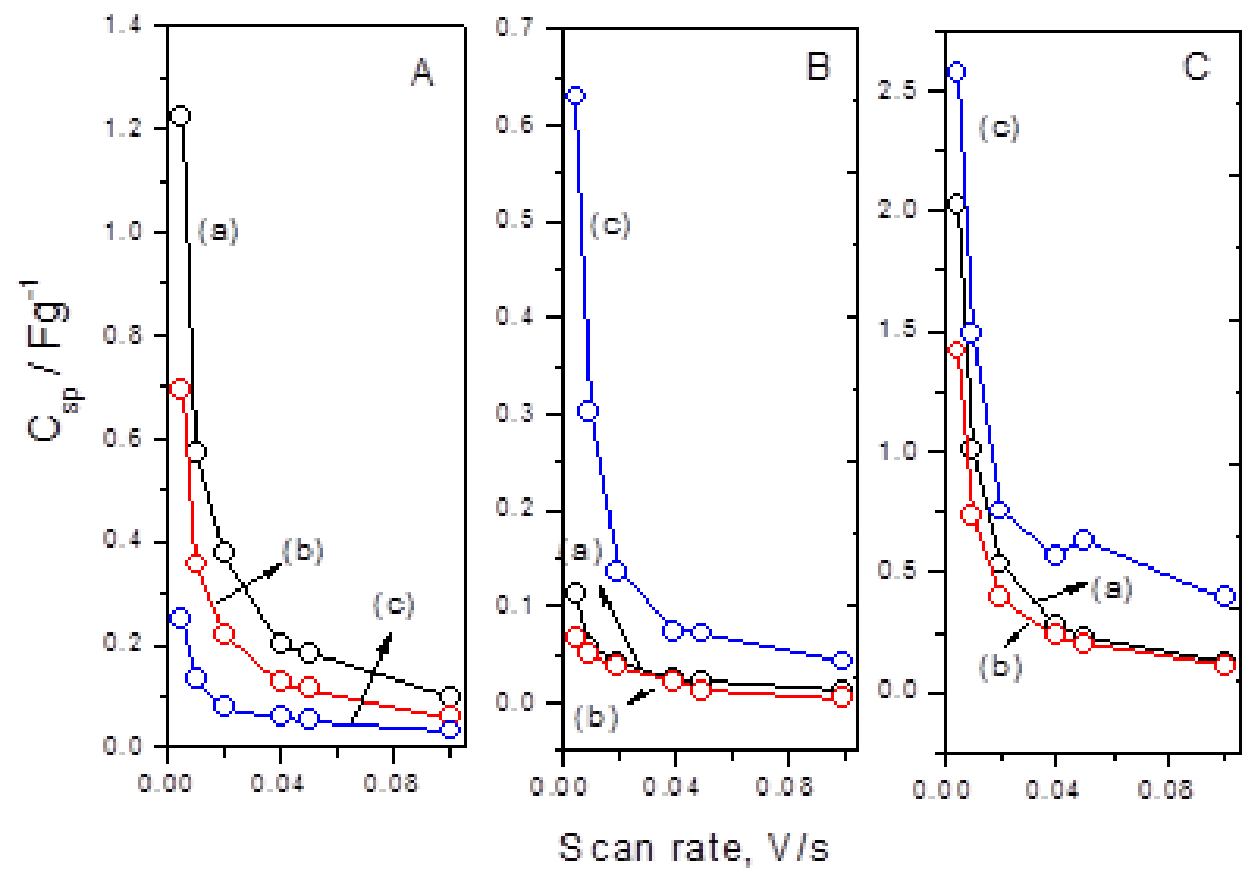

Figure 5. Plot of specific capacitance of carbon electrode (A) CCP, (B) CPPWOT and (C) CCPHNO3 versus scan rate in $\mathrm{H}_{2} \mathrm{SO}_{4}$ (a) $4 M$, (b) $2 \mathrm{M}$ and (c) $1 M$.
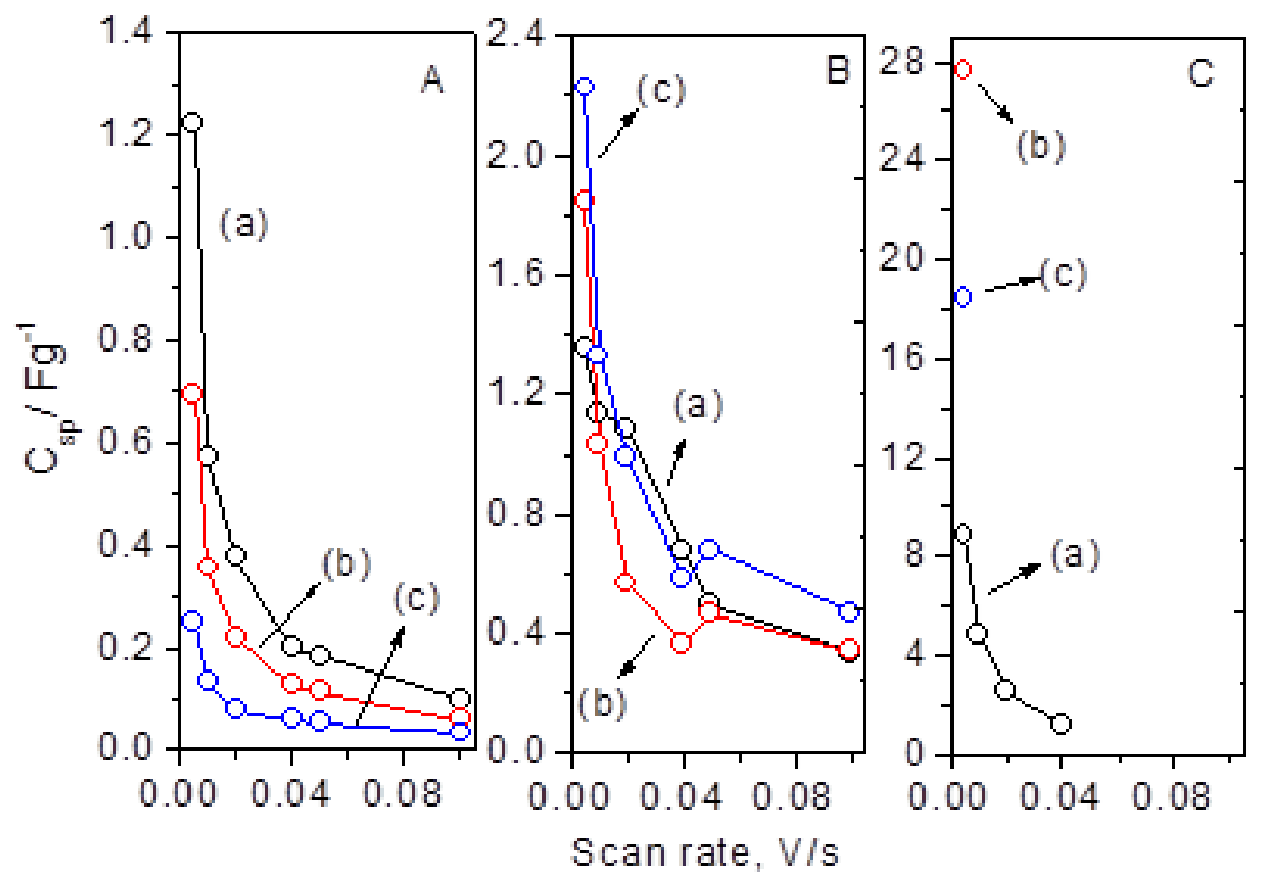

Figure 6. Plot of specific capacitance $\left(C_{s p}\right)$ of carbon electrode (A) CCP, (B) CPPWOT and (C) CCPHNO3 versus scan rate in $\mathrm{KOH}$ (a) $4 \mathrm{M}$, (b) $2 \mathrm{M}$ and (c) $1 \mathrm{M}$.

The presence of the micropores in the activated carbon are unique for Gelam wood. Combining their uniqueness, simplicity of the preparation method and the abundance availability, makes these electrode materials relatively inexpensive and environmentally friendly. Thus Gelam wood activated carbon has the potential to be developed as electrodes in electrochemical capacitors. 


\section{Conclusions}

The three types of electrodes, namely CCP, CCPHNO3 and CCPWOT, prepared from Gelam wood activated carbon, have different surface morphologies which basically contained many micropores. CCP has continuous - smooth surface and contains very few grain boundaries. On the other hand CCPWOT and CCPHNO3 have rough surfaces and contain many cracks. The different oxidation methods using nitric acid and water steam gave different effects on the surface area of the carbons. Acid nitric oxidation led to a larger pore volume and surface area, while water steam oxidation led the opposite effect. In addition, CCPHNO3 had relatively large amounts of micropores. The presence of surface oxides was important factor in improving the capacitance of electrode and increased the effective utilization of the pore structure. CCPHNO3 had the highest capacitance value of $27.68 \mathrm{~F} \mathrm{~g}^{-1}$ while the specific capacitance of the electrode CCPWOT was similar to CCP, at 2.23 and $1.22 \mathrm{~F} \mathrm{~g}^{-1}$, respectively.

\section{References}

[1] M. Jayalakshmi, K. Balasubramanian, Int. J. Electrochem. Sci. 3 (2008) 1196-1217

[2] W. Li, H. Probstle, J. Fricke, J. Non-Cryst. Solids 325 (2003) 1-5

[3] A.G. Pandolfo, A.F. Hollenkamp, J. Power Sources 157 (2006 ) 11-27

[4] E. Taer, M. Deraman, I.A. Talib, A. Awitdrus, S.A. Hashmi, A.A. Umar, Int. J. Electrochem. Sci. 6 (2011) $3301-3315$

[5] C. Merino, P. Soto, E. Vilaplana-Ortego, J.M.G.d. Salazar, F. Pico, J.M. Rojo, Carbon 43 (2005) 551-557

[6] H.P. Boehm, Carbon 32 (1994) 759-769

[7] C. Nieto-Delgado, M. Terrones, J.R. Rangel-Mendez, Biomass Bioenerg. 35 (2011) 103-112

[8] S. Villar-Rodil, A. Martinez-Alonso, J.A. Pajares, J.M.D. Tascon, M. Jasienko-Hałat, E. Broniek, J. Kaczmarczyk, A. Jankowska, A. Albiniak, T. Siemieniewska, Micropor. Mesopor. Mat. 64 (2003) 11-19

[9] K.P. Gadkaree, M. Jaroniec, Carbon 38 (2000) 983-993

[10] K. Ramakrishnan, C. Namasivayam, Sustain. Environ. Res. 19 (2009) $173-178$

[11] C. Du, N. Pan, Nanotechnology 17 (2006) 5314-5318

[12] R. Nickolov, D. Kovacheva, M. Mladenov, N.Velichkova, R. Raicheff, P. Tzvetkova, J. Univ. Chem. Tech. Metall. 46 (2011) 275-282

[13] K. Xia, Q. Gao, J. Jiang, J. Hu, Carbon 46 (2008) 1718-1726

[14] H. Aripin, L. Lestari, D. Ismail, S. Sabchevski, Open Mat. Sci. J. 4 (2010) 117-124

[15] M.J. Bleda-Martınez, J.A. Macia-Agullo, D. Lozano-Castello, E. Morallon, D. Cazorla-Amoros, A. Linares-Solano, Carbon 43 (2005) 2677-2684

[16] L.L. Zhang, X. Zhao, H. Ji, M.D. Stoller, L. Lai, S. Murali, S. Mcdonnell, B. Cleveger, R.M. Wallace, R.S. Ruoff, Energy Environ. Sci. 5 (2012) 9618-9625

[17] B.G. Choi, Y.S. Huh, W.H. Hong, H.J. Kim, H.S. Park, Nanoscale 4 (2012) 5394-5400

[18] E. Frackowiak, F. Beguin, Carbon 39 (2001) 937-950

[19] M. Seredych, D. Hulicova-Jurcakov, G.Q. Lu, T.J. Bandosz, Carbon 46 (2008) 1475-1388

(C) 2013 by the authors; licensee IAPC, Zagreb, Croatia. This article is an open-access article distributed under the terms and conditions of the Creative Commons Attribution license (http://creativecommons.org/licenses/by/3.0/) 